\title{
Drying Performance, as well as Physical and Flexural Properties of Oil Palm Wood Dried via the Super-Fast Drying Method
}

\begin{abstract}
Mohd Rafsan Rais, ${ }^{\mathrm{a}}$ Edi Suhaimi Bakar, ${ }^{\mathrm{a}}$ Zaidon Ashaari, ${ }^{\mathrm{a}}$ Lee Seng Hua, ${ }^{\mathrm{b}, *}$ Mojtaba Soltani, ${ }^{\mathrm{c}}$ Farid Ramli, ${ }^{\mathrm{a}}$ and Paiman Bawon ${ }^{\mathrm{a}, *}$

Effects of incising parameters were studied relative to the drying performance and properties of super-fast dried oil palm wood. Different incising depths $(1 / 3,1 / 2,2 / 3$, and $100 \%$ of the total thickness) and distance (38 $\mathrm{mm}$ and $50 \mathrm{~mm}$ ) were made on the oil palm wood boards prior to the super-fast drying procedure. All the boards achieved the desired moisture content after drying. Drying defects were minimal, as only two boards indicated end checks and surface checks defects. The board density ranged from $0.44 \mathrm{~g} / \mathrm{m}^{3}$ to $0.60 \mathrm{~g} / \mathrm{m}^{3}$, and the thickness swelling and water absorption of the boards ranged from $8.3 \%$ to $12.5 \%$ and $45 \%$ to $67 \%$, respectively. The specific modulus of rupture and elasticty ranged from $0.35 \mathrm{~N} \mathrm{~m}^{3} / \mathrm{kg} \mathrm{mm}^{2}$ to $0.77 \mathrm{~N} \mathrm{~m}^{3} / \mathrm{kg} \mathrm{mm}^{2}$ and from $77.64 \mathrm{~N} \mathrm{~m}^{3} / \mathrm{kg} \mathrm{mm}^{2}$ to $118.40 \mathrm{~N} \mathrm{~m}^{3} / \mathrm{kg} \mathrm{mm}^{2}$, respectivily. It can be concluded that the hole distances did not exert significant effect on the properties, with exception of specific modulus of elasticity. A hole depth of $1 / 3 \mathrm{~mm}$ was preferable, since the surface looked like no incision had been made and the sample had good physical and flexural properties.
\end{abstract}

Keywords: Incising parameter; Drying performance; Oil palm wood; Super-fast drying method

Contact information: a: Faculty of Forestry and Environment, Universiti Putra Malaysia, 43400 UPM Serdang, Selangor, Malaysia; $b$ : Institute of Tropical Forestry and Forest Products, Universiti Putra Malaysia, 43400 UPM Serdang, Selangor, Malaysia; c: Department of Wood and Paper Science and Technology, Islamic Azad University, Chalous Branch, P.O. Box 46615/397, Mazandaran 46619/61367 Iran; *Corresponding author:lee_seng@upm.edu.my; paiman@upm.edu.my

\section{INTRODUCTION}

The shift from solid wood to lignocellulosic biomass appears to be a plausible longterm alternative that guarantees a sustainable supply for the wood-based industry. Lignocellulosic biomass has been recognised for its potential. Among these resources, oil palm trunk (OPT) has been noted by researchers, as Malaysia generates abundant amounts of OPT every year. The annual OPT production in Malaysia is projected at 7 million metric tonnes, approximately 75 tonnes per hectare (Konga et al. 2014). For disposal purposes, most of the trunks are left in the field and serve as natural nutrient source for soils or are burned for waste disposal. However, a freshly felled trunk is rich in moisture and very unlikely to burn without additional physical processing during replantation. Futhermore, enviromental concerns, e.g., insects, pests, and stem rotten fungi, can be important as well (Lim and Gan 2005; Abdullah 2010; Bhat et al. 2010).

Unlike commercial timber, OPT has drawbacks, including poor strength and durability, low dimensional instability, and bad machining properties (Bakar et al. 2013). Therefore, a number of comprehensive techniques and methods have been developed to 
enhance these properties and low melocular weight phenolic resin treatment through a modified compreg method is the most preferable, as it pratically improves the properties within a short period of time and the treated samples can be used as a value added product, e.g., furniture and handicrafts (Bakar 2000; Bakar et al. 2005).

However, the drying process has always been a bottleneck for oil palm wood (OPW) production. Drying can be defined as an improtant stage that needs a large amount of energy and time (Muhammad Nadzim et al. 2021). Oil palm wood is a well-known material that has the ability to hold a high moisture content. The water in the material can range from 1.5 to 2.5 times the weight of the dry substrate as it grows from the outer to the core of the tree, and it marginally decreases from the bottom to the top of the tree (Lim and Gan 2005; Anis et al. 2016). Previous study reported that drying OPW by kiln drying method required 7 to 12 days with recovery rate of only $18.26 \%$ while the remaining lumber $(81.7 \%$ ) was considered as a waste (Balfas 2006; Anis et al. 2016). Therefore, in order to solve the drying problem of OPW, new and unique method has to be invented through modifiying the previous drying methods.

Recently, a new and efficient drying method has been developed by Bakar et al. (2016). This method is a unique method consisting of a 2-step drying process with the inclusion of holes to the material surface. It was reported that this method is capable of drying medium and low density OPW in just $3 \mathrm{~h}$ without or nearly free of defects. However, this approach has several limitations, as the existence of the holes ultimately hinders the usage of the dried OPW boards. Therefore, this study introduced a new system in the superfast drying method to replace a full-hole process with aim to overcome the limitations. Unlike the full-hole process, this study created incomplete holes $(1 / 3,1 / 2,2 / 3$ of the thickness of OPW) on the surface based on the boards thickness where the other surface presenting the clean and smooth surface. This practice could widen the applications of the OPW boards such as multilayer solid wood composites, door panels, acoustic panels, building elements like glued laminated timber and solid wood multi-layer panels where the holes can be hidden with lamination. The physical and flexural characteristics of dried OPW boards and the effects of depths of holes and distances between holes were assessed.

\section{EXPERIMENTAL}

\section{Materials Preparation}

The oil palm lumber boards were prepared from 40-year-old matured oil palm trunks using a modified cant sawing pattern. The samples (with dimension of $1200 \mathrm{~mm}(\mathrm{~L})$ x $200 \mathrm{~mm}(\mathrm{~W})$ x $30 \mathrm{~mm}(\mathrm{~T}))$ were treated using a 5\% borax solution to prevent fungal attack and was segragated to the inner part and outer part based on the initial moisture content (Bakar et al. 2016). In this study, only the outer part was used; the samples that had a moisture content less than $200 \%$ were considered the outer part.

\section{Incising Process}

A total of 64 samples board with 4 replications for each test were incised with a fixed drill bit with a $7 \mathrm{~mm}$ diameter, based on a previous study by Bakar et al. (2016). Different hole depths $(1 / 3,1 / 2,2 / 3$, and $100 \%$ of the sample thickness), and holes distances (38 $\mathrm{mm}$ and $50 \mathrm{~mm}$ ) were incised on the samples in a diagonal pattern, as shown in Fig. 1 and 2. Meanwhile, clear samples without holes were prepared for comparison purposes. 


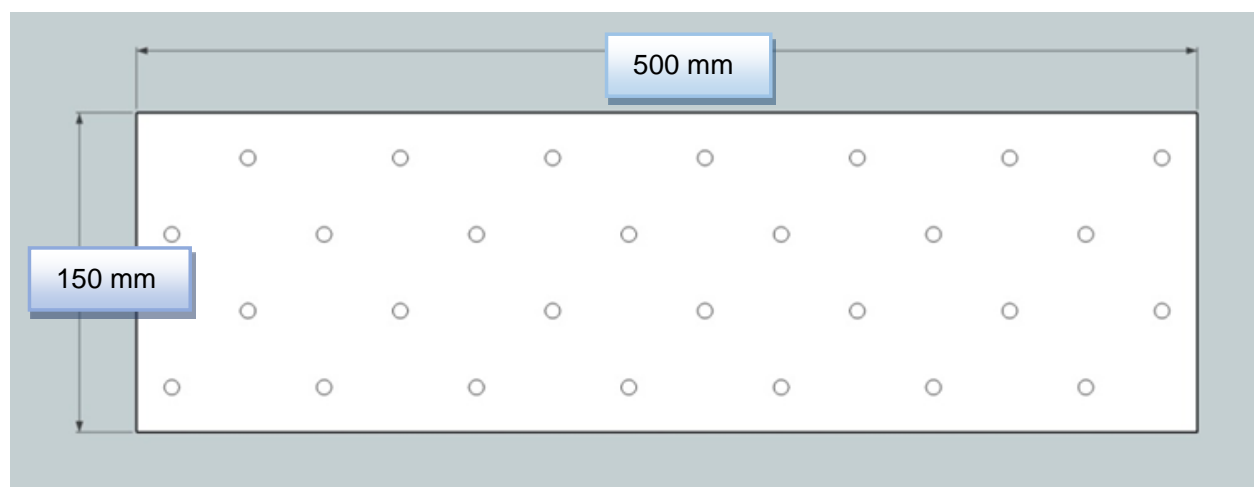

Fig. 1. Holes at the surface of oil palm wood boards with diagonal pattern with distance of $38 \mathrm{~mm}$ and $50 \mathrm{~mm}$

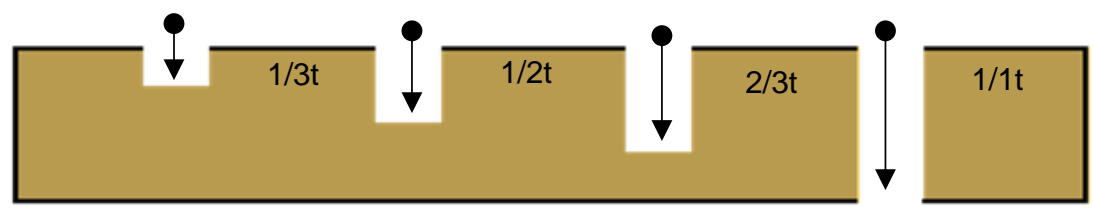

Fig. 2. Hole depth of oil palm wood boards

\section{Super-Fast Drying Method (SFD)}

This super-fast drying method for oil palm wood is unique, involving hole-drilling and 2-step drying: hot plates drying to a certain MC, followed by high-temperature kiln drying to a target MC as shown in Fig. 3. Drying conditions are summarized in Table 2.

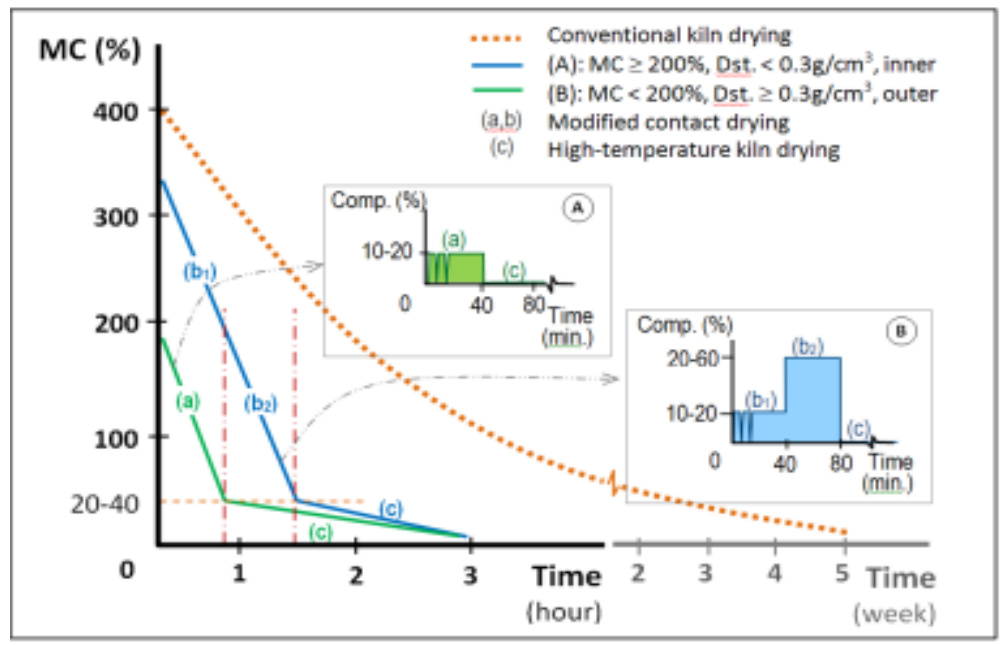

Fig. 3. The super-fast drying process in comparison with conventional kiln drying (Bakar et al. 2016)

Table 2. Drying Conditions of Super-fast Drying Method

\begin{tabular}{lcccc}
\hline \multicolumn{1}{c}{ Stage } & $\begin{array}{c}\text { Temperature } \\
\left({ }^{\circ} \mathbf{C}\right)\end{array}$ & Time & $\begin{array}{c}\text { Pressure } \\
(\text { PSI) }\end{array}$ & CR (\%) \\
\hline $\begin{array}{l}\text { 1.Hot-plate drying } \\
\text { 2.High-temperature kiln }\end{array}$ & 180 & $40 \mathrm{~m}$ & 1000 & $10-20 \%$ \\
drying & 100 & $3 \mathrm{~h}$ & - & - \\
\hline${ }^{*} \mathrm{CR}=$ compression ratio (\%), Bakar et al. 2016 & & &
\end{tabular}


The incised OPW samples were dried using hot pressing with a low compression extent (10\% to $20 \%)$ at $180{ }^{\circ} \mathrm{C}$ for $40 \mathrm{~min}$ followed by high temperature drying for $3 \mathrm{~h}$ until the desired moisture content was achieved (less than 10\%). The samples were conditioned at ambient temperature $\left(25^{\circ} \mathrm{C} \pm 3{ }^{\circ} \mathrm{C}\right)$ for one week. The drying method was performed according to the patent number PI 2016702162 (Bakar et al. 2016).

\section{Properties Evaluation}

Determination of density

The conditioned test samples, with a moisture content less than $10 \%$, were weighed to determine their mass, and their length, width, and thickness were measured. The density of the samples was calculated according to Eq. 1,

$$
\operatorname{Density}\left(\mathrm{kg} / \mathrm{m}^{3}\right)=\frac{m}{v}
$$

where $m$ is the mass $(\mathrm{g})$ of the samples after being conditioned and $V$ is the volume $\left(\mathrm{mm}^{3}\right)$ of the sample after being conditioned.

\section{Drying performance and drying defects}

The test samples were cut into dimensions of $150 \mathrm{~mm}$ x $500 \mathrm{~mm}$ with a thickness of $30 \mathrm{~mm}$. To increase the precision of each parameter, three replicates of the tests were carried out. The test specimens then underwent the super-fast drying process mentioned aboved.The final MC were measured according to Eq. 2. When the drying process was completed, the test samples were immediately re-examined. The grade of the test specimens was determined, and the presence and extent of stress-caused lumber defects were identified and tallied. Finally, all visible defects were carefully remeasured using the accepted procedures detailed in Scholl et al. (2008). In Eq. 2, $W_{\mathrm{i}}$ is the initial weight of the samples $(\mathrm{g})$ and $W_{\text {od }}$ is the oven dried weight of the samples $(\mathrm{g})$.

$$
M C(\%)=\frac{W_{i}-W_{o d}}{W_{o d}} \times 100
$$

\section{Water absorption and thickness swelling}

The test specimens with dimensions of $50 \mathrm{~mm} \times 50 \mathrm{~mm}$ were weighed, and the thickness was measured before being submerged in $25 \mathrm{~mm}$ of distilled water maintained at a temperature of $20{ }^{\circ} \mathrm{C} \pm 1{ }^{\circ} \mathrm{C}$. After $2 \mathrm{~h}$ of submersion, the water was removed and the specimens were drained for $10 \mathrm{~min} \pm 2 \mathrm{~min}$ to remove any excess surface water. The specimens were weighed, and the thickness of the specimens was measured immediately. After that, the specimens were submerged for an additional $22 \mathrm{~h}$, followed by the weighing and measuring procedures mentioned earlier. After submersion, the results were averaged, and based on ASTM standard D1037 (2012), the water absoption (WA) and thickness swelling (TS) were determined according to Eqs. 3 and 4.

$$
\begin{aligned}
& W A(\%)=\frac{W_{f}-W_{i}}{W_{i}} \times 100 \\
& T S(\%)=\frac{f_{f}-f_{i}}{f_{i}} \times 100
\end{aligned}
$$


In Eqs. 3 and $4, W_{\mathrm{f}}$ is the weight final of the samples and $W_{\mathrm{i}}$ is the weight inital of the samples.meanwhile, $f_{\mathrm{f}}$ is the final thickness of the samples and $f_{\mathrm{i}}$ is the intial thickness of the samples.

\section{Flexural test}

The flexural strength of both the treated and untreated samples were evaluated in accordance to the test procedures specified in ASTM standard D143 (2014) using an Instron universal testing machine (INSTRON 5567) under the following conditions: a temperature of $23{ }^{\circ} \mathrm{C} \pm 2{ }^{\circ} \mathrm{C}$, a relative humidity of $50 \% \pm 10 \%$, and a load capacity of 30 $\mathrm{kN}$. The load was applied continuously throughout the test at a cross-head speed of 6.35 $\mathrm{mm} \mathrm{min}^{-1}$. The modulus of rupture (MOR) and modulus of elasticity (MOE) were determined according to Eqs. 6 and 7,

$$
\begin{aligned}
& \operatorname{MOR}(\mathrm{MPa})=\frac{3 p_{m} L^{3}}{2 b h^{2}} \\
& \operatorname{MOE}(\mathrm{MPa})=\frac{p_{t} L^{3}}{4 D b h^{3}}
\end{aligned}
$$

where $p_{\mathrm{m}}$ is the maximum breaking load $(\mathrm{MPa}), p_{\mathrm{t}}$ is the load at below the proportional limit (MPa), $L$ is the span of the test specimen $(\mathrm{mm}), D$ is the deflection of the midspan resulting from a load at below the proportional limit $(\mathrm{mm}), b$ is the breadth or width $(\mathrm{mm})$, and $h$ is the height or depth ( $\mathrm{mm}$ ) of the test sample. To eliminate the effect of OPW density on the testing result, the MOE and MOR were divided by the density of the sample. This value is known as the specific modulus of elasticity (sMOE) and specific modulus of rupture (sMOR). The results were analyzed via one way analysis of variance (ANOVA) to determine the effect of the parameters. The mean of each sample was evaluated via Duncan's post hoc test at a 5\% confidence level. All statistics were computed using the Statistical Package for Social Science (SPSS, version 22, IBM, Armonk, NY).

\section{RESULTS AND DISCUSSION}

\section{Drying Conditions of Dried OPW Board}

Table 3 shows the drying schedule of the dried OPW boards with different incising parameters. The boards with $38 \mathrm{~mm}$ and $50 \mathrm{~mm}$ hole distances achieved their desired moisture content after the first drying process. Generally, drilling holes in the wood increases the surface area for water to evaporate and shortens the travelling distance of water from the core to the surface (Simpson 1985). Thus, an increased drying rate was observed. The first drying process, called modified contact drying method, which involved a hot-plate where the board was compressed to approximately $10 \%$ to $20 \%$ of its thickness. The compression has also resulted in the creation of multiple microscopic splits in the impermeable pit membranes of hardwoods, which in turn assist in facilitating the drying rate (Chech 1971). A recent study by Hamzah et al. (2017), which used a 6-step treatment method, also claimed that the compression of wood causes cracks in the wood, which facilitated drying and hence reduced the drying time. However, the first process may not be fast enough to remove all the water vapor from the internal surface due to the short pressing time. Therefore, the process was followed by a high-temperature kiln-drying and as a result, a significant reduction in the moisture content was observed, with minimal defects $(5 \%$ or lower). 
Table 3. Moisture Content (MC) of Oil Palm Wood Board with Different Incising Parameters at Different Drying Stages

\begin{tabular}{|c|c|c|c|c|c|c|}
\hline \multirow{3}{*}{ Hole Distance } & \multirow{3}{*}{ Depth of hole } & \multicolumn{4}{|c|}{ Moisture content $(\%)^{*}$} & \multirow{3}{*}{$\begin{array}{c}\text { Drying } \\
\text { defect } \\
(\%)\end{array}$} \\
\hline & & \multirow{2}{*}{$\begin{array}{c}\text { Hot-plate } \\
\text { Drying }\end{array}$} & \multicolumn{3}{|c|}{ High Temperature Drying (3h) } & \\
\hline & & & $1 \mathrm{~h}$ & $2 \mathrm{~h}$ & $3 \mathrm{~h}$ & \\
\hline \multirow{4}{*}{$38 \mathrm{~mm}$} & $1 / 3 t$ & 3.15 & 1.06 & 0.40 & 0.40 & \multirow{4}{*}{$<5 \%$} \\
\hline & $1 / 2 \mathrm{t}$ & 5.11 & 1.12 & 0.13 & 0.13 & \\
\hline & $2 / 3 t$ & 7.14 & 3.96 & 1.00 & 1.00 & \\
\hline & Full hole & 6.64 & 2.57 & 2.57 & 2.57 & \\
\hline \multirow{4}{*}{$50 \mathrm{~mm}$} & $1 / 3 t$ & 7.25 & 1.53 & 0.24 & 0.24 & \multirow{4}{*}{$<5 \%$} \\
\hline & $1 / 2 \mathrm{t}$ & 5.01 & 1.36 & 0.27 & 0.27 & \\
\hline & $2 / 3 t$ & 7.13 & 3.12 & 1.02 & 1.02 & \\
\hline & Full hole & 8.40 & 2.28 & 0.48 & 0.48 & \\
\hline
\end{tabular}

* Variation in MC value after each process of super-fast drying method; $t=$ thickness of the oil palm wood board

In terms of recovery, a previous study reported that $70 \%$ of 20 -year-old OPW dried via kiln drying had severe drying defects, e.g., warping, collapses, deep surface, and internal checks, whereas the remaining 30\% had mild to no defects (Anon. 2002). In this study, 34 boards were assessed and only one board presented end checks and one board presented surface checks, as shown in Figs. $4 \mathrm{a}$ and $4 \mathrm{~b}$, respectively. These results were close to the findings by Bakar et al. (2016), who claimed that this drying method was successful in reducing the amounts of defects to $5 \%$ or lower.

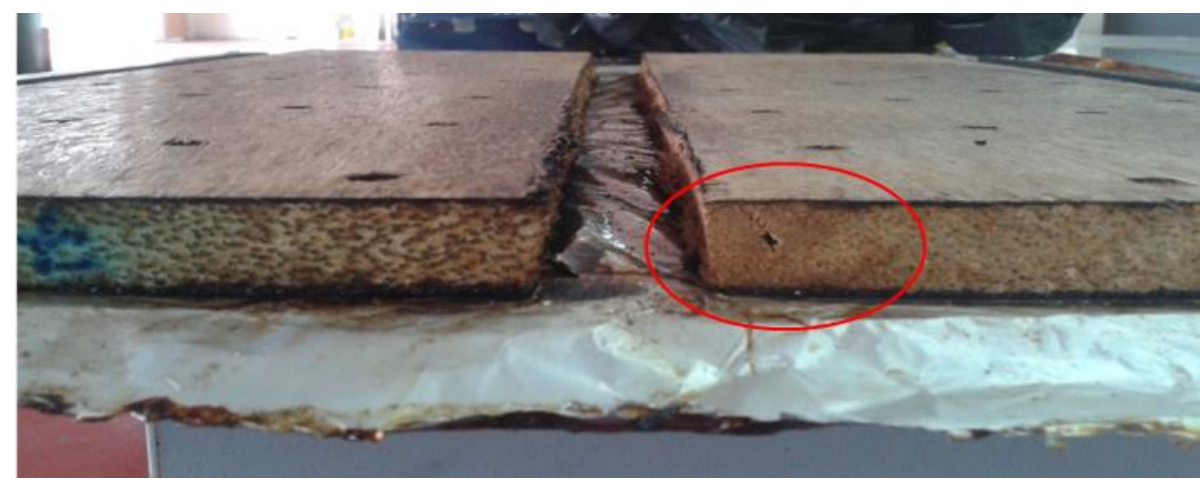

(a)

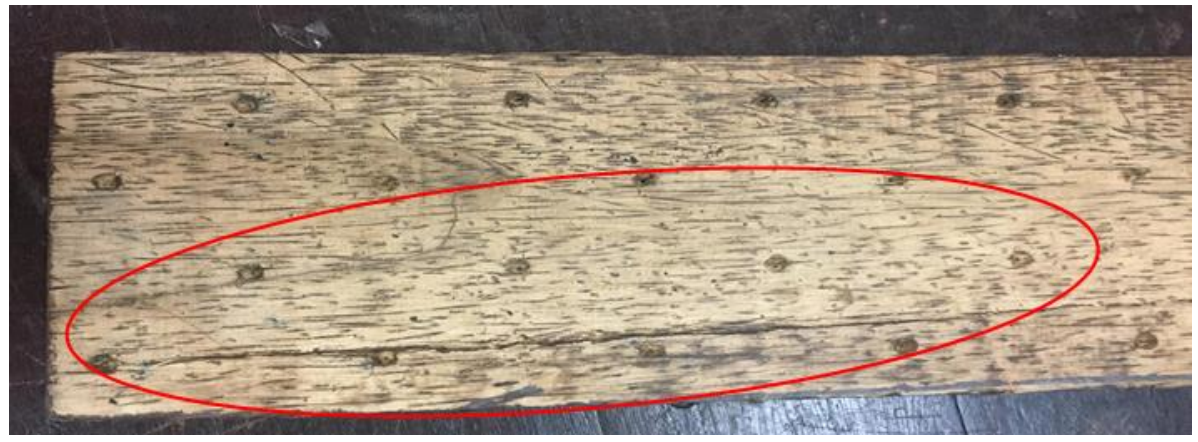

(b)

Fig. 4. Drying defects after the super-fast drying method: (a) End checks of the OPW board; and (b) Surface checks of the OPW board 


\section{Property Characterization}

Density of the dried-OPW boards

Figure 5 shows the density of the OPW boards with different incising parameters. The density of the dried boards in this study ranged from $0.44 \mathrm{~g} / \mathrm{m}^{3}$ to $0.60 \mathrm{~g} / \mathrm{m}^{3}$ compared to untreated OPW which recorded a density of $0.21 \mathrm{~g} / \mathrm{m}^{3}$. It was notable that the density of the boards improved regardless of the hole depth and distance. The increasing density of the boards was related to the compression applied. The first step in super-fast drying method used compression extents between $10 \%$ and $20 \%$, which increased the density of the material. The dried OPW boards with a $50 \mathrm{~mm}$ hole distance had a greater density compared to the boards with a $38 \mathrm{~mm}$ hole distance. On a fixed surface area basis, a long incising distance means a lower number of holes were drilled on the surface, which resulted in a lower mass loss during the process of making the holes and led to higher density. Meanwhile, a 1/3-hole depth represented the highest density value among the other samples, as shown in Fig. 5. Similar to the incising distance, the dried OPW boards with a shallow incised depth lost less mass compared to the other samples, and therefore had a higher density.

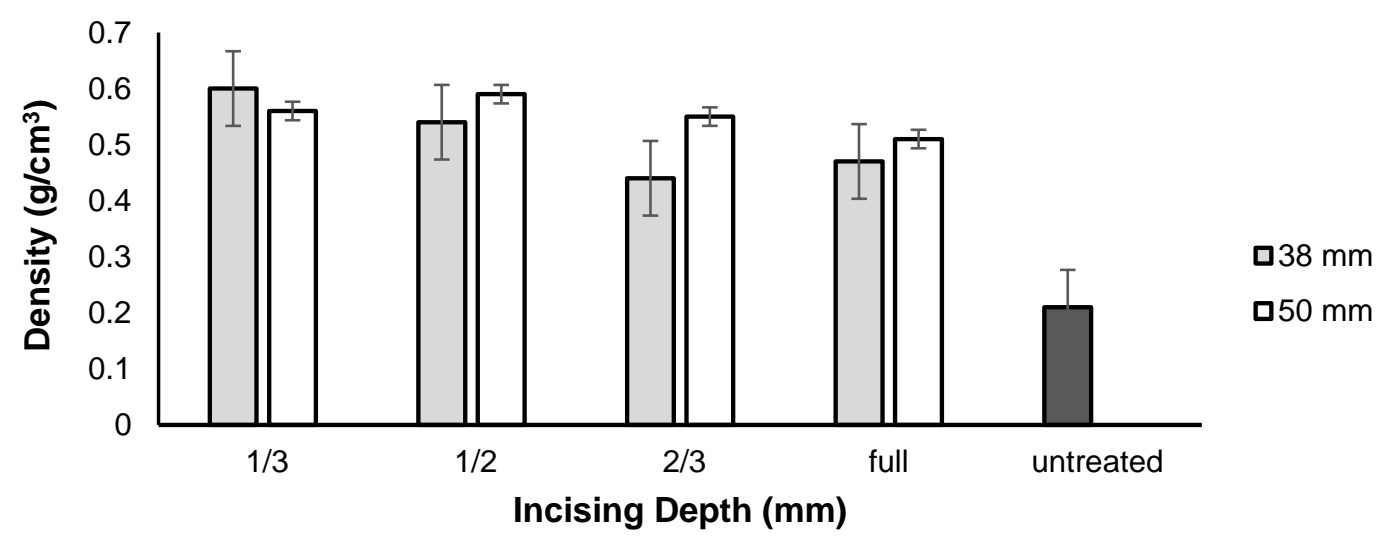

Fig. 5. Density of the dried-OPW boards with different hole depths and distances

\section{Water absorption and thickness swelling of the dried-OPW boards}

The thickness swelling (TS) value indicates the dimensional stability of the samples. The TS of the dried OPW boards with different hole depths and distances after 2 $\mathrm{h}$ and for $24 \mathrm{~h}$ water submersion is shown in Figs. 6 and 7. The result show that the samples swelled up between $6 \%$ to $7 \%$ for the first $2 \mathrm{~h}$ of submersion and $8 \%$ to $9 \%$ after $24 \mathrm{~h}$ of submersion Regardless of depth, a $50 \mathrm{~mm}$ hole distance yielded a higher TS compared to a $38 \mathrm{~mm}$ hole distance for both $2 \mathrm{~h}$ and $24 \mathrm{~h}$ water submersion. A similar increasing trend occurred among samples with different hole depths at $2 \mathrm{~h}$ and $24 \mathrm{~h}$ of submersion, with the mean value ranging from $8.3 \%$ to $12.5 \%$. The TS value of all the dried samples was higher than the untreated samples after $24 \mathrm{~h}$ of soaking. Oil palm wood has a very porous anatomical structure, and it can easily absorb water without substantial swelling occurring. The increasing TS value with an increasing submersion time could be explained by the significant spring back after pressing.

This statement was supported by studies by Wong et al. (1999), Unsal et al. (2011), and Choowang and Hiziroglu (2015), who all mentioned that compressive stresses are released after the pressing process. In addition, Aizat et al. (2017) found that the inconsistent TS pattern, along with the increasing compression rate ratio of laminated 
compreg OPW, were caused by the spring-back phenomena that offset the treatments. The mean values for the super-fast dried OPW in terms of water absorption (WA) are shown in Figs. 8 and 9. It was found that the WA of dried OPW board was significantly lower than the untreated samples. Similar to the TS values, the value of WA also exhibited an increasing trend after $24 \mathrm{~h}$ of submersion for all depths, which ranged from $45 \%$ to $67 \%$, and the lowest values were recorded at $1 / 3$ and $1 / 2$ depths, respectively. The lower WA values were related to the fixation of the parenchyma cell wall and the degradation of a portion of the hemicelluloses at high temperatures (Choowang and Hiziroglu 2015).

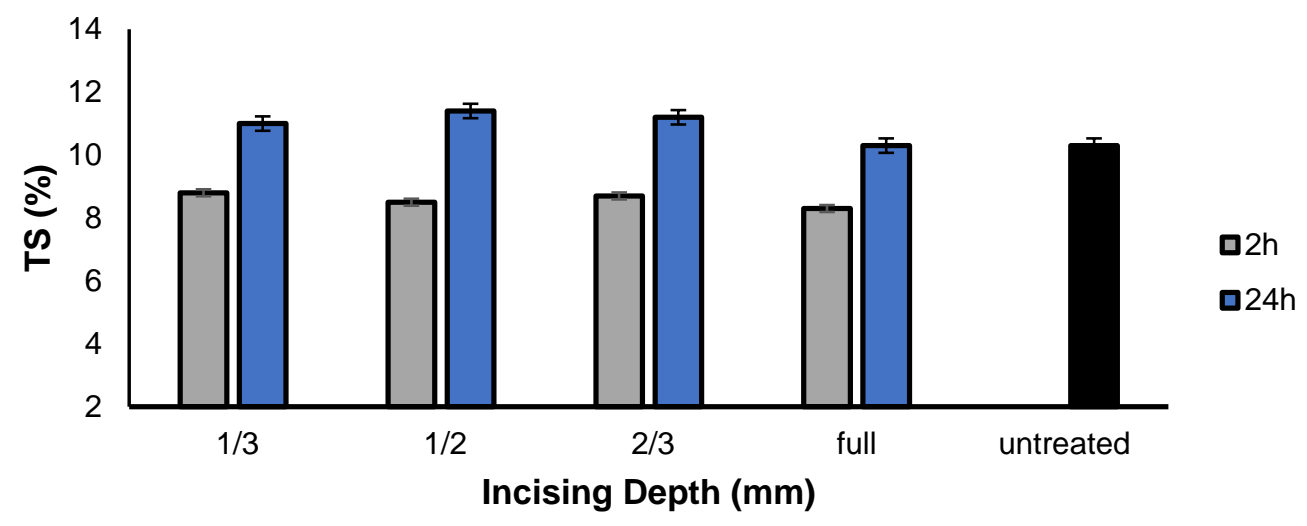

Fig. 6. Thickness swelling of the dried-OPW boards with $38 \mathrm{~mm}$ hole distances

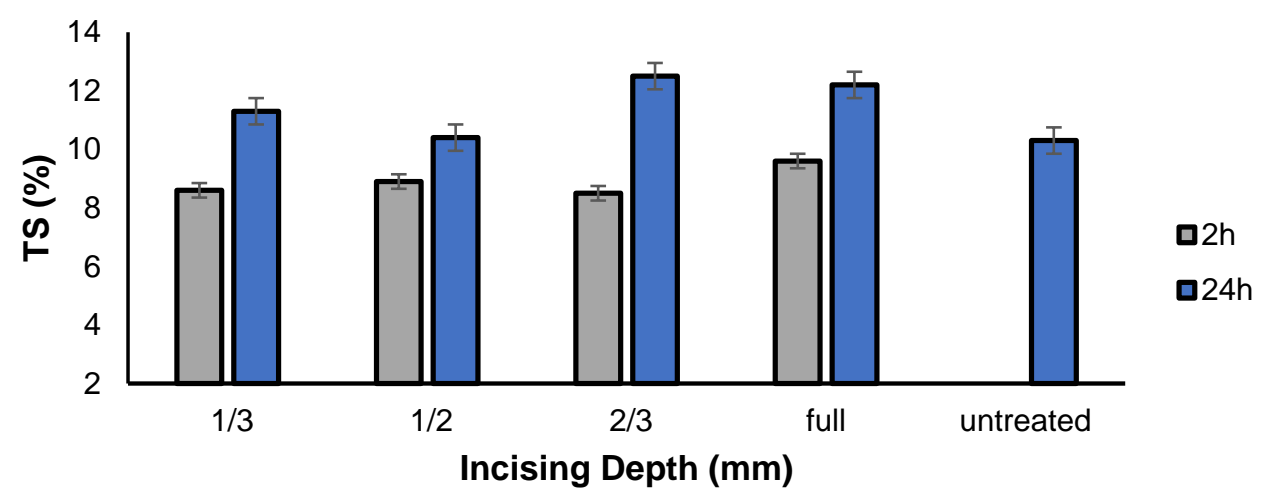

Fig. 7. Thickness swelling of the dried-OPW boards with $50 \mathrm{~mm}$ hole distances

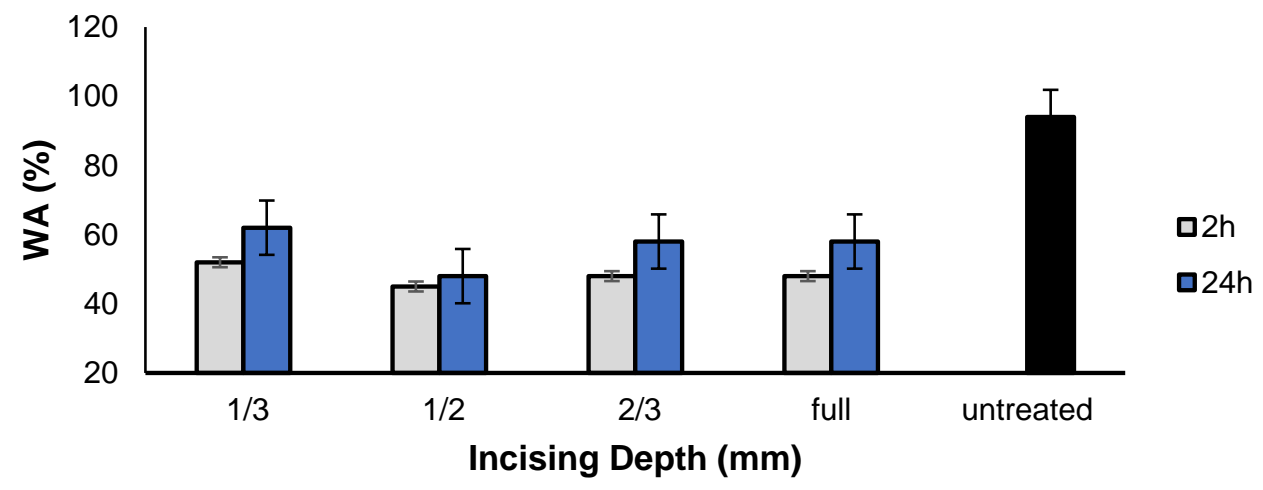

Fig. 8. Water absorption of the dried-OPW boards with $38 \mathrm{~mm}$ hole distances 


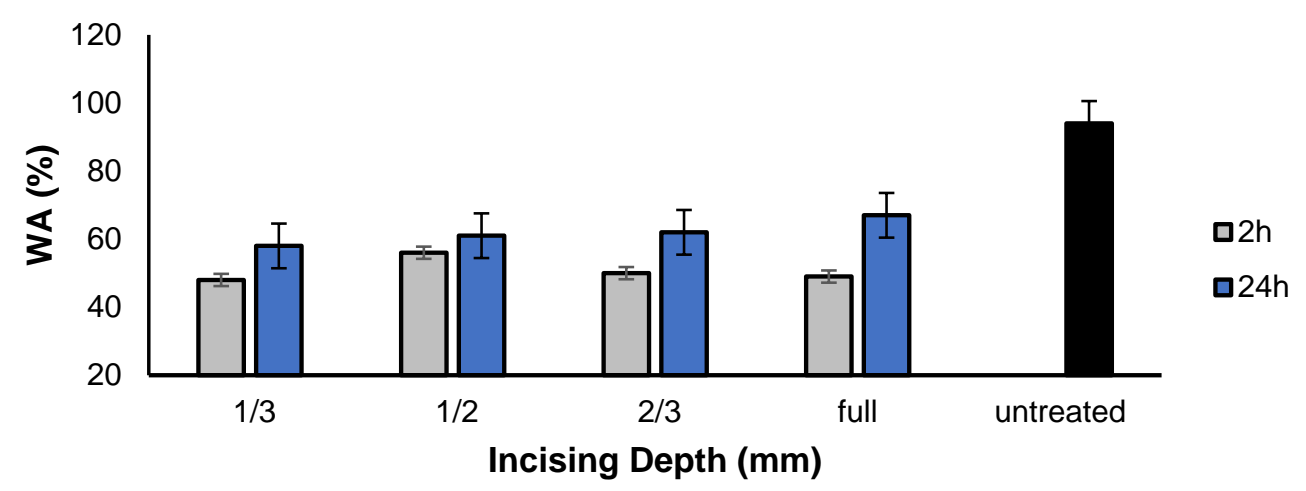

Fig. 9. Water absorption of the dried-OPW boards with $50 \mathrm{~mm}$ hole distances

\section{Mechanical properties}

Figures 10 and 11 summarize the mean values of the mechanical properties of dried OPW boards. It is notable that the specific MOR and MOE values of the dried OPW were higher than that of the untreated OPW due to the compression employed in the super-fast drying process.

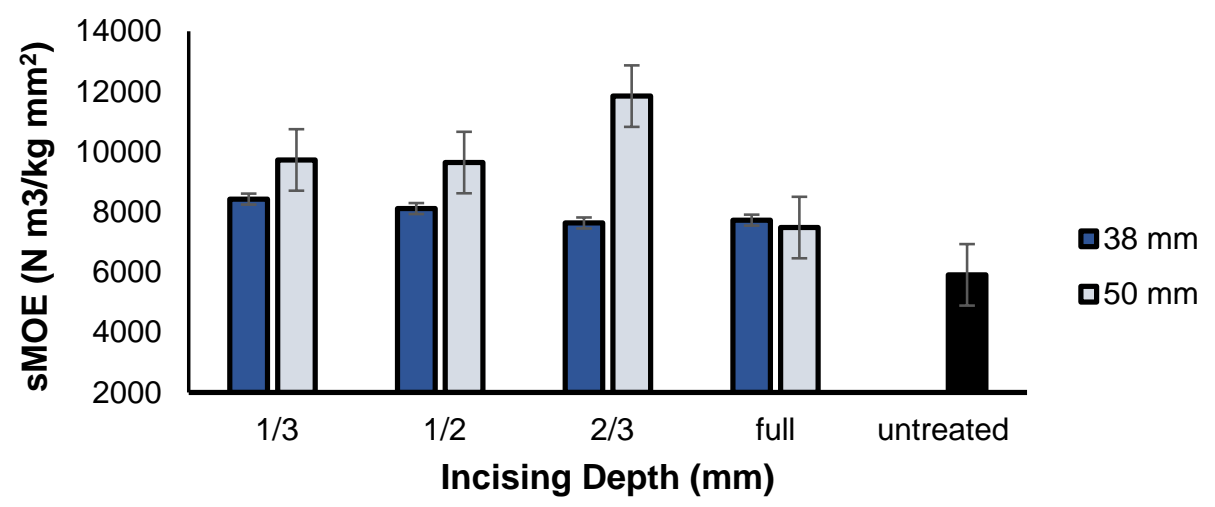

Fig. 10. Specific MOE the dried-OPW boards with different incising depths and hole distances

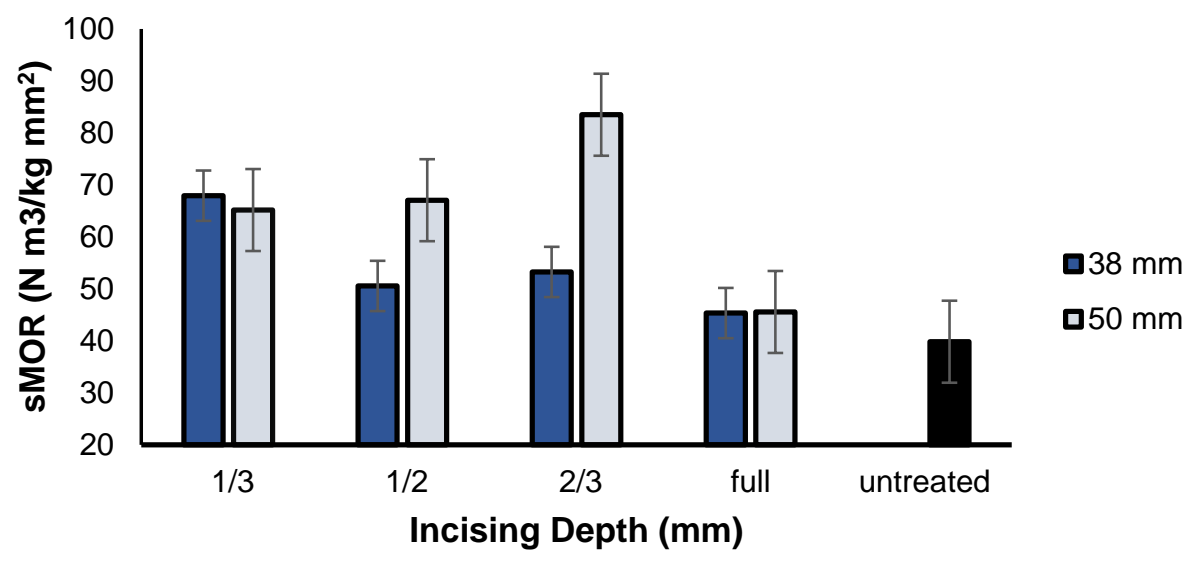

Fig. 11. Specific MOR the dried-OPW boards with different incising depths and hole distances 
Generally, OPW boards with $50 \mathrm{~mm}$ hole distance had higher specific MOR and MOE than boards with $38 \mathrm{~mm}$ hole distance. Larger distance between the holes $(50 \mathrm{~mm})$ means lower mass loss and longer fibers and therefore provides stronger mechanical properties. As for the effects of incising depths, OPW board with smaller distance between holes $(38 \mathrm{~mm})$ showed a decreasing trend as the incising depth increased from $1 / 3$ of its original thickness to fully drilled through. This result was in agreement with the studies by Kass (1975), Perrin (1978), Winandy (1995), and Elkins et al. (2007), which found that the addition of incisions will reduce the strength properties of the samples. In addition, Winandy (1995) and Elkins et al. (2007) also stated that the strength loss was related to the material size and incision depth and density (number of incisions per unit area). The most appropriate theory to predict strength loss from incising was originally proposed by Luxford and Zimmerman (1923). This theory holds that the effect of the incising process is directly related to the change in section modulus induced by incising. Contrarily, for OPW board with larger distance between holes $(50 \mathrm{~mm})$, the specific MOR and MOE increased as the incising depth increased from $1 / 3$ to $2 / 3$ of the original thickness of the OPW boards. It is, however, decreased when full holes were incised. This could be due to the fact that the loss of materials' volume could be neglected when larger distance between holes $(50 \mathrm{~mm})$ was used in comparison to smaller distance between holes $(38 \mathrm{~mm})$. Instead, the OPW boards become more compressible, which resulted in a more rigid and hard materials as the incising depth continued to increase from $1 / 3$ to $2 / 3$ of the original thickness of the OPW boards until a breaking point was reached (fully holed). This could be shown by the high thickness swelling experienced by OPW boards with $50 \mathrm{~mm}$ hole distances and 2/3 depth (Fig. 7) as the extent of spring back is higher in those OPW boards.

\section{CONCLUSIONS}

1. Using this super-fast drying method, the moisture content (MC) of the oil palm wood (OPW) could be reduced to $10 \%$ within 3 to $4 \mathrm{~h}$ accompanied with defects of lower than $5 \%$.

2. Hole distance and the hole depth affected the physical and mechanical properties of the dried OPW to different extents.

3. The hole distance did not exert significant effects on the properties of OPW, with the exception of the some, for which OPW boards with $50 \mathrm{~mm}$ hole distance have higher sMOE than boards with $38 \mathrm{~mm}$ hole distance.

4. As for the hole depth, OPW board with smaller distance between holes $(38 \mathrm{~mm})$ showed a decreasing trend as the incising depth increased from $1 / 3$ of its original thickness to fully drilled through. However, a totally different trend was observed in the samples with larger distance $(50 \mathrm{~mm})$.

5. Overall, it can be concluded that the smaller distance between holes and lower depth of drilling is preferable when taking both physical and mechanical properties into consideration. 


\section{ACKNOWLEDGMENTS}

The authors wish to give thanks for the financial support provided by the Geran University Putra Malaysia (GP) GP/2018/9650000 and Higher Institutions' Centre of Excellence (HICoE) (Project code: UPM/INTROP/100-13/9/3/HICoE/6369107).

\section{REFERENCES CITED}

Abdullah, C. K. (2010). Impregnation of Oil Palm Trunk Lumber (OPTL) Using Thermoset Resins for Structural Applications, Master's Thesis, Universiti Sains Malaysia, Penang, Malaysia.

Aizat, G., Zaidon, A., Lee, S. H., Eedi., S. B., and Paiman, B. (2017). “A comparison between the properties of low and medium molecular weight phenol formaldehyde resin-treated laminated compreg oil palm wood," International Forestry Review 19(S3), 1-11. DOI: 10.1505/146554817828562305

Anis, M., Noor, A. S., Ismail, S., Halimah, M., and Astimar, A. A. (2016). "Recovery of oil palm lumber," Journal Palm Oil Developments 64, 7-10.

Anonymous (2002). Final Year Project. Project Research and Development of an Alternative Building Material from Agro Waste - Oil Palm Trunk, Universiti Malaya \& Institut Penyelidikan Perhutanan Malaysia, Kulua Lumpur.

ASTM D1037-12 (2012). "Standard test methods for evaluating properties of wood-base fiber and particle panel materials," ASTM International, West Conshohocken, PA.

ASTM D143-14 (2014). "Standard test methods for small clear specimens of timber," ASTM International, West Conshohocken, PA.

Bakar, E. S., Soltani, M., Paridah, M. T., and Choo, A. C. Y. (2016). "Oil palm lumber drying method and system thereof," Patent number: PI2016702162, Intellectual Property Corporation of Malaysia (MyIPO), Bangsar, Kuala Lumpur.

Bakar, E. S., Tahir, P. M., Sahri, M. H., Noor, M. S. M., and Zulkifli, F. F. (2013). "Properties of resin impregnated oil palm wood (Elaeis guineensis Jack)," Pertanika Journal Tropical Agriculture Science 36(S), 93-100.

Bakar, E. S., Tahir, P. M., Sahri, M. H., and Yap, H. S. (2005). "Oil palm wood treated with pf resin by the compreg method: Influence of solution concentration and impregnation period," in: Proceedings of the International Symposium on Wood Science and Technology, 27-30 November, Yokohama, Japan, pp. 86-87.

Bakar, E. S. (2000). Utilization of Oil Palm Trunk as Housing and Furniture Material, Universiti Putra Malaysia, Selangor, Malaysia.

Balfas, J. (2006). "New approach to oil palm wood utilization for woodworking production Part 1: Basic properties," Indonesian Journal of Forestry Research 3, 5565. DOI:10.20886/ijfr.2006.3.1.55-65.

Bhat, I. u. H., Abdullah, C. K., Abdul Khalil, H. P. S., Ibrahim, M. H., and Nurul Fazita, M. R. (2010). "Properties enhancement of resin impregnated agro waste: Oil palm trunk lumber," Journal of Reinforced Plastics and Composites 29(22), 3301-3308. DOI: $10.1177 / 0731684410372262$

Chech, M. (1971). "Dynamic transverse compression treatment to improve drying behavior of yellow birch," Forest Products Journal 21(2), 41-50.

Choowang, R., and Hiziroglu, S. (2015). "Properties of thermally-compressed oil palm trunks (Elaeis guineensis)," Journal of Tropical Forest Science 27(1), 39-46. 
Elkins, L., Morrell, J. J., and Leichti, R. J. (2007). "Establishing a through-boring pattern for utility poles," Wood and Fiber Science 39(4), 639-650.

Hamzah, H. H., Bakar, E. S., Ashaari, Z., and Lee, S. H. (2017). “Assessment of oil palm wood quality improvement through integrated treatment process as function of sawing pattern and slab thickness," Journal of Oil Palm Research 29, 366-372. DOI: 10.21894/jopr.2017.2903.09

Kass, A. J. (1975). "Effect of incising on bending properties of redwood dimension lumber," Report No. FPL-RP-259, U. S. Department of Agriculture, Forest Products Laboratory, Madison, WI.

Konga, S. H., Loh, S. K., Bachmann, R. T., Rahim, S. A., and Salimon, J. (2014). "Biochar from oil palm biomass a review of its potential and challenges," Renewable and Sustainable Energy Reviews 39, 729-739. DOI: 10.1016/j.rser.2014.07.107

Lim, S. C., and Gan, K. S. (2005). "Characteristics and utilization of oil palm stem," Timber Technology Bulletin No. 35, Forest Research Institute Malaysia, Selangor, Malaysia.

Luxford, R. E., and Zimmerman, C. W. (1923). "Effect of perforations on the strength and treatment of Douglas fir (air-dried)," Report No. L-119-10), U. S. Department of Agriculture, Forest Products Laboratory, Madison, WI.

Muhammad Nadzim, M. N., Edi, S. B., Mojtaba, S., Zaidon, A., and Lee, S. H. (2021). "Drying of oil palm lumber by combining air force drying and modified superfast drying methods," Journal of Oil Palm Research, Article in press. DOI: 10.21894/jopr.2021.0002

Perrin, P. W. (1978). "Review of incising and its effects on strength and preservative treatment of wood," Forest Products Journal 28(2), 27-33.

Scholl, M. S., Wiedenbeck, J. K., Blankenhorn, P. R., Ray, C. D., Stover, L. R., and Beakler, B. W. (2008). "A comparison of kiln-drying schedules and quality outcomes for 4/4-thickness black cherry lumber san from small-diameter logs," Forest Products Journal 58(12), 41-48.

Simpson, W. T. (1985). "Process for rapid conversion of red oak logs to lumber," Forest Products Journal 35(1), 51-56.

Unsal, O., Zeki, C., Umit, B., Suleyman, K., Chang, Y. S., and Yeo, H. M. (2011). "Effect of thermal compression treatment on the surface hardness, vertical density propile and thickness swelling of eucalyptus wood boards by hot-pressing," Journal of the Korean Wood Sceince and Technology 39(2), 148 -155. DOI:

10.5658/WOOD.2011.39.2.148

Winandy, E. J. (1995). "Influence of time-to-failure on strength of CCA-treated lumber," Forest Products Journal 45(2), 82-85.

Wong, E. D., Zhang, M., Wang, Q., and Kawai, S. (1999). "Formation of the density profile and its effects on the properties of particleboard," Wood Science and Technology 33, 327-340. DOI: 10.1007/s002260050119

Article submitted: October 20, 2020; November 27, 2020; Revised version received: January 13, 2021; Accepted: January 15, 2021; Published: January 21, 2021.

DOI: 10.15376/biores.16.1.1674-1685 